\title{
Measurement, Temporal-spatial Evolution Characteristics and Countermeasures of High-quality Agricultural Development in China
}

\author{
Yu Zhao, Jichan Zhu, Yu Zhang* \\ School of Economics and Management, East China University of Technology, Nanchang 330013, China
}

\begin{abstract}
The evaluation system of China's high-quality agricultural development is constructed from four aspects: efficiency improvement, innovation-driven, green development, and coordinated sharing, which level is measured based on the entropy weight method (EWM), Besides, using the Theil index decomposition, spatial clustering and convergence theory, this paper analyzes the temporal-spatial evolution characteristics of high-quality agricultural development from 2003 to 2017 . The results show that it has obvious spatial agglomeration and convergence in China. First, the quality of China's agricultural development has steadily improved; besides, the provinces with it are mainly concentrated in the major grain-producing areas in the Northeast Plain and the Yangtze River Basin. Second, it is characterized by conditional convergence in China, and there are also club convergence in major grain-producing areas and non-major grain-producing areas. Third, the conditional convergence rate is $0.067-0.071$, the half-life is about 11-12 years, the conditional convergence rate of the main and the non-main production area are 0.095 and 0.075 , and the half-life is about 8 years and 10 years, respectively. Finally, combined with the specific statistical indicators, this paper sorted out the reasons restricting the high-quality development of agriculture in various regions and put forward the corresponding countermeasures.
\end{abstract}

\section{Introduction}

Delivered at the 19th session of national congress of the Communist Party of China (CPC) pointed out that China's economy has transited from a stage of rapid growth to a stage of high-quality development. As the foundation of national economy and the strategic industry related to national security, the high-quality development of agriculture is the key aspect of the high-quality development of national economy. General Secretary Xi Jinping has repeatedly pointed out that "To get stronger, China's agriculture must be strong", "we must adhere to the main line of supply-side structural reform in agriculture, take the road of quality-based agriculture, and implement the strategy of quality-based agriculture", and "strengthening agriculture is the foundation for ensuring the safety of the people and the key of national governance ". The Central Document No. 1 in 2019 states that it is necessary to vigorously develop the production of scarce and green high-quality agricultural products, and promote the transformation of agriculture from an increase in production to a quality improvement. At the same time, the current agricultural development in China is facing prominent contradictions, including alleviating the pressure on resources and environment, meeting the people's escalating consumer demand and coping with the fierce international competition. It can be said that promoting the high-quality development of agriculture is not only a clear requirement of the central government, but also an internal need of agricultural development in the new era, even more the key and urgent task to promote the agricultural supply-side structural reform, improve the agricultural international competitiveness and achieve the high-quality development of national economy.

In recent two years, the connotation of high quality development has been discussed in academic circles, which has been deeply studied by many scholars, that is, high-efficiency, fair and green sustainable development aimed at meeting the growing needs of the people for a better life [1]. High-quality economic development is defined as the economic development mode, structure and power state that can better meet the people's growing real needs [2]. High-quality development is not simply pursuing economic aggregates and economic growth, but paying more attention to the balanced development of economy, society, and the environment [3]. In terms of development characteristics, high-quality economic development includes dimensions such as sufficiency, coordination, innovation, and sustainability [4]. Specifically, from the perspective of changes in social contradictions, high-quality agricultural development emphasizes more on the multi-dimensional coordination and progress of economy, ecology, environment and society [5]. From the perspective of supply-demand and

"Corresponding author: 1765674144@qq.com 
input-output, high-quality agricultural development means high-quality agricultural supply system quality, high-quality agricultural industry and international competitiveness.

Although the idea of high-quality development has been widely accepted, there is still no unified expression recognized by all sectors of society. Based on the existing results, it is found that the design of the evaluation index system for agricultural high-quality development is in its infancy. In fact, most domestic and foreign scholars focus on index measurement and evaluation, but there are few researches on the temporal-spatial characteristics, trends and causes of the high-quality development of provincial agriculture. The marginal contribution of this research lies in the following: first, improving and supplementing the connotation of high-quality agricultural development, and enriching and expanding the relevant evaluation index system; second, scientifically measuring the level of high-quality agricultural development in China, and accurately identifying regional differences, evolutionary trends in high-quality agricultural development, and restrictive factors to provide empirical support for the decision-making department to accurately judge its realization path.

\section{Indicator and Data Source}

The construction of an indicator system based on the five development concepts can reflect the laws of economic development and is scientific to a certain extent. With reference to the existing index system for high-quality economic development, combined with the characteristics of the agricultural economy, four dimensions of efficiency improvement, innovation-driven, green development and coordinated sharing are selected to fit the high-quality agricultural development indicators. Considering representativeness, comprehensiveness and availability, the indicator system includes 21 sets of three-level indicators. Table 1 reports the index system of agricultural high-quality development.

This paper deconstructs the high-quality agricultural development into four parts: efficiency improvement indicator, innovation-driven indicator, green development indicator and coordination and sharing indicator. Among them, the efficiency improvement indicator is mainly represented by grain yield, output value of agricultural, forestry, animal husbandry and fishery employees per capita, disposable income of farmers per capita, efficiency of agricultural machinery, and cultivated land area reflecting agricultural scale effect per capita. The innovation-driven indicator is represented by the ratio of agricultural added value to intermediate consumption, the proportion of rural primary and secondary school teachers with high educational background and high quality in the rural population, the proportion of agricultural technical training personnel in the rural population, the proportion of improved seed area in cultivated land, and the number of applications for new crop variety rights per capita. The green development indicator is characterized by the consumption of diesel oil, pesticide, agricultural film, chemical fertilizer and energy intensity of agriculture, forestry, animal husbandry and fishery. The coordinated sharing indicator includes the producer price indicator ratio of agricultural products and industrial products that reflects the "Scissors Difference" between workers and farmers, the income ratio of urban and rural residents reflecting urban and rural wealth differences, the percentage of agricultural expenditure in total fiscal expenditure reflecting "industry nurturing agriculture", and the number of rural elderly care service institutions per capita reflecting the equalization of social public services, the number of clinics per capita in rural areas, and subsistence allowances for the rural poor per capita.

Table 1 The measurement indicator system of the high-quality agricultural development level

\begin{tabular}{|c|c|c|c|c|c|}
\hline Grade I index & Grade II index & Grade III index & Unit & Effect & Weight \\
\hline \multirow{10}{*}{$\begin{array}{l}\text { The } \\
\text { high-quality } \\
\text { agricultural } \\
\text { development }\end{array}$} & \multirow{5}{*}{$\begin{array}{l}\text { Efficiency } \\
\text { improvement }\end{array}$} & Grain yield & Ton/mu & + & 0.068 \\
\hline & & $\begin{array}{c}\text { Output value of agricultural, forestry, } \\
\text { animal husbandry and fishery } \\
\text { employees per capita }\end{array}$ & $\begin{array}{c}10000 \\
\text { yuan/person }\end{array}$ & + & 0.212 \\
\hline & & $\begin{array}{c}\text { Disposable income of farmers per } \\
\text { capita }\end{array}$ & $\begin{array}{c}10000 \\
\text { yuan/person }\end{array}$ & + & 0.216 \\
\hline & & Efficiency of agricultural machinery & 10000 yuan $/ \mathrm{kw}$ & + & 0.207 \\
\hline & & Cultivated land area per capita & Hectare/person & + & 0.296 \\
\hline & \multirow{5}{*}{$\begin{array}{l}\text { Innovation- } \\
\text { driven }\end{array}$} & $\begin{array}{l}\text { The ratio of agricultural added value } \\
\text { to intermediate consumption }\end{array}$ & & + & 0.084 \\
\hline & & $\begin{array}{c}\text { The proportion of rural primary and } \\
\text { secondary school teachers in the rural } \\
\text { population }\end{array}$ & $\%$ & + & 0.156 \\
\hline & & $\begin{array}{l}\text { The proportion of agricultural } \\
\text { technical training personnel in the } \\
\text { rural population }\end{array}$ & $\%$ & + & 0.180 \\
\hline & & $\begin{array}{l}\text { The proportion of improved seed area } \\
\text { in cultivated land }\end{array}$ & $\%$ & + & 0.247 \\
\hline & & The number of applications for new & Item/ 10000 & + & 0.333 \\
\hline
\end{tabular}




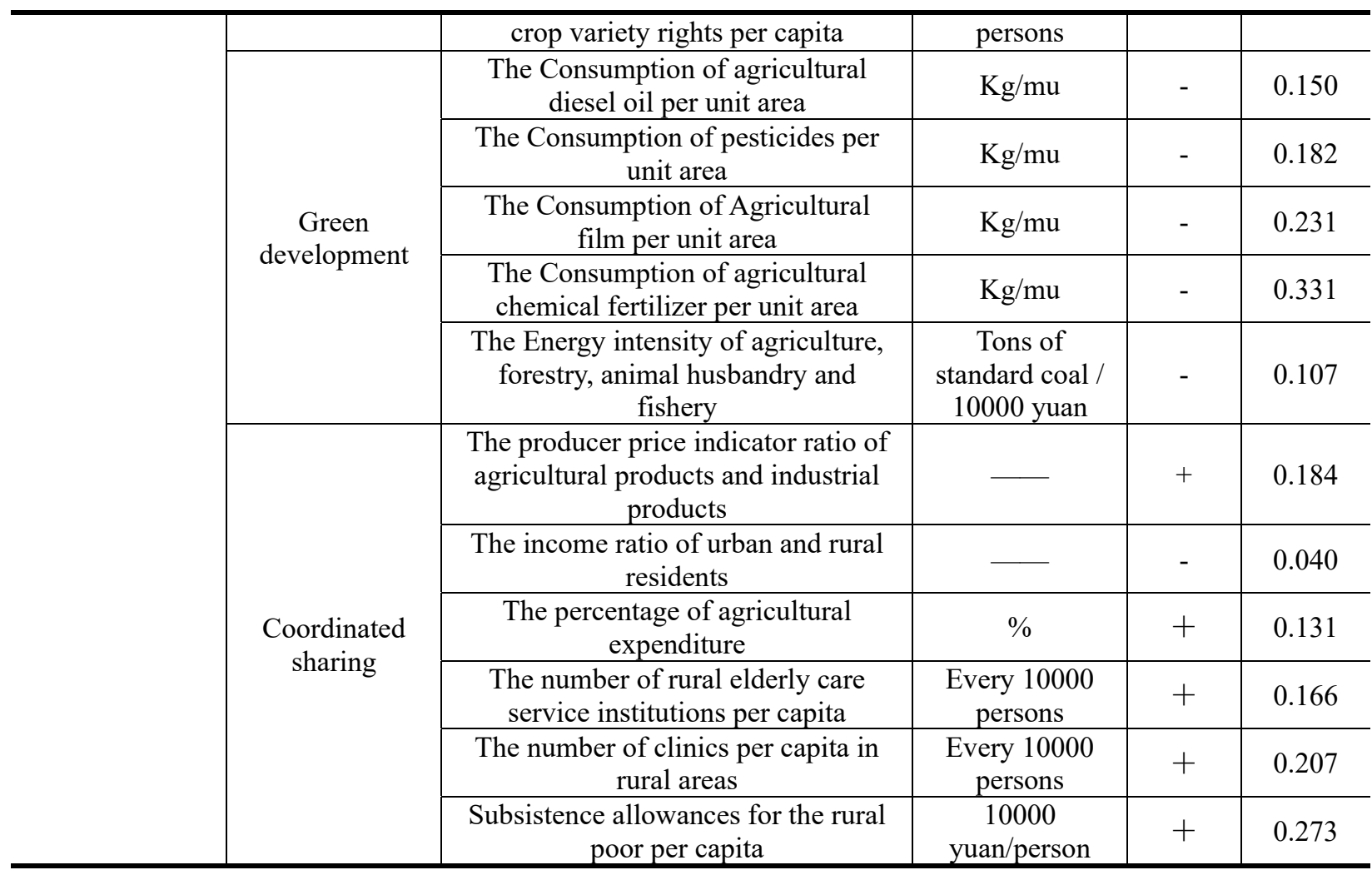

Note: The "+ (-)" in the "Effect" column indicates a positive (negative) index. The larger (smaller) the value, the larger (smaller) the contribution to the grade II index. The index weight is calculated by the entropy weight method.

smaller the intervention on the weight. This article takes

\section{Methods}

\subsection{Entropy Weight Method}

The entropy method determines the weight based on the initial information provided, and is not interfered by subjective factors such as expert cognition. In order to compare the changes in the high-quality agricultural development index of various provinces in different years, the entropy weight method is applied to the processing of panel data. The specific calculation of the panel entropy method is as follows: the panel data in the high-quality agricultural development index system is non-dimensionally processed, $\mathrm{X}_{\mathrm{tij}}$ is the normalized value and $\mathrm{V}_{\mathrm{tij}}$ is the original value of the $\mathrm{j}$-th index in the $\mathrm{i}$-th area in the $t$ period, 1 is the number of periods, $n$ is the number of regions, and $\mathrm{m}$ is the number of indicators. The positive and negative index values are normalized by formulas (1) and (2) respectively. Equation (1) represents the distance between the deviation of the index value and the minimum value relative to the range, reflecting that the larger the index value, the larger the normalized value. Equation (2) reflects that the smaller the index value, the larger the normalized value.

$$
\begin{aligned}
& X_{t i j}=\left[V_{t i j}-\min \left(V_{t i j}\right)\right] \div\left[\max \left(V_{t i j}\right)-\min \left(V_{t i j}\right)\right] \\
& 1 \leq t \leq l, 1 \leq i \leq n \quad 1 \leq t \leq l, 1 \leq i \leq n \quad 1 \leq t \leq l, 1 \leq i \leq n \\
& \left.\left.X_{t i j}=\underset{1 \leq t \leq l, 1 \leq i \leq n}{[\max }\left(V_{t i j}\right)-V_{t i j}\right] \div \underset{1 \leq t \leq l, 1 \leq i \leq n}{[\max }\left(V_{t i j}\right)-\min \left(V_{t i j}\right)\right]
\end{aligned}
$$

$\mathrm{Y}_{\mathrm{tij}}$ represents the value of index $\mathrm{j}$ after translation, and parameter A represents the distance of translation. Because $A>\left|\min \left(X_{t i j}\right)\right|$ and the smaller the value of $\mathrm{A}$, the
$\mathrm{A}=0.1$ and the translation formula is $\mathrm{Y}_{\mathrm{tij}}=\mathrm{X}_{\mathrm{tij}}+\mathrm{A}$. Mark the proportion of the $\mathrm{i}$-th area in the $\mathrm{j}$-th index in period $\mathrm{t}$ as $B_{t i j}$, the entropy value of the $\mathrm{j}$-th index as $e_{j}$, the information utility value as $\mathrm{g}_{\mathrm{j}}$, and the weight as $\mathrm{w}_{\mathrm{j}}$. The weight can be obtained by formulas (3)-(6). The score $Z_{t i}$ of the $\mathrm{i}$-th region in the $\mathrm{t}$ period on the grade II index can be obtained by formula (7). With reference to Huang Qinghua's research [15], the dimensionless grade II index scores are summed and averaged to get the high-quality agricultural development index.

$$
\begin{gathered}
B_{t i j}=Y_{t i j} / \sum_{t=1}^{l} \sum_{i=1}^{n} Y_{t i j}(t=1,2, \ldots l ; i=1,2, \ldots n ; j=1,2, \ldots m) \\
e_{j}=-k / \sum_{t=1}^{l} \sum_{i=1}^{n} B_{t i j}, k=1 / \ln (l \times n) \\
g_{j}=1-e_{j} \\
w_{j}=g_{j} / \sum_{j=1}^{m} g_{j} \\
Z_{t i}=\sum_{j=1}^{m} w_{j} X_{i t j}
\end{gathered}
$$

\subsection{The Theil Index Decomposition}

The Theil index is used to measure the provincial differences in high-quality agricultural development. Based on the Theil index decomposition method, the overall differences are further decomposed into intra-regional and inter-regional differences, so as to analyze the structure and the sources of differences. The total Theil index of each province is marked as $T_{p}$, the Theil index representing the difference in high-quality agricultural development within region $i$ is recorded as $\mathrm{T}_{\mathrm{wi}}$, and the Theil index representing the difference 
between regions is recorded as $\mathrm{T}_{\mathrm{b}}$. $\mathrm{N}_{\mathrm{ij}}$ and $\mathrm{Y}_{\mathrm{ij}}$ respectively represent the rural population and high-quality agricultural development index in the $\mathrm{j}$-th province of region $\mathrm{i}$. $\mathrm{T}_{\mathrm{p}}$ is decomposed as follows:

$$
T_{p}=\sum_{i} \sum_{j}\left(\frac{Y_{i j}}{Y}\right) \ln \left(\frac{Y_{i j} / Y}{N_{i j} / N}\right)=\sum_{i}\left(\frac{n_{w i}}{n} \times \frac{\bar{e}_{w i}}{\bar{e}} \times T_{w i}\right)+T_{b}
$$

Among them, $n_{u i} / n$ represents the proportion of provinces in each region, and $\bar{e}_{w i} / \bar{e}$ represents the ratio of the average value of the agricultural high-quality development index between the provinces of each region and the country.

\subsection{Convergence Analysis}

Convergence is the basis of regional coordinated development. The policy implications of convergence lies in formulating policies scientifically to better coordinate regional development. The $\beta$-convergence coefficient formula derived by Barro in the neoclassical economic framework is the most widely used model in convergence analysis [6]. When Young analyzed the economic convergence of American counties, he constructed a panel $\beta$ convergence model based on the Barro model [7]. On this basis, a spatial panel $\beta$ convergence model is constructed to analyze the convergence characteristics of high-quality agricultural development. The spatial lag term of equation (9) can correct the parameter estimation deviation caused by the omitted spatial effect. Marked the high-quality agricultural development index as $\mathrm{y}, \mathrm{y}_{\mathrm{i}, \mathrm{t}}$ represents the high-quality agricultural development index of the i-th area in year $t$, and $y_{i}$, to represents the high-quality agricultural development index of the $\mathrm{i}$-th area in year $\mathrm{t}_{0}$. On this basis, the per capita GDP X of each region in period $t_{0}$ is added to the model as the initial conditions for convergence to examine the conditional convergence of high-quality agricultural development in each region, that is to investigate whether the regional economic base is the condition of its convergence. The $\beta$ in the coefficient $-\left[\left(1-\mathrm{e}^{-\beta \mathrm{T}}\right) / \mathrm{T}\right]$ is the conditional convergence rate, and $\mathrm{T}$ represents the interval span of the sample. When $X$ is not included in the model, the coefficient $\beta$ describes the absolute convergence rate. After calculating the convergence rate, the half-life of the convergence of high-quality agricultural development in each region is calculated according to $-\ln (0.5) / \beta[8]$. The half-life of convergence measures the number of years required for the gap between backward and developed regions to be reduced by half. On the basis of formula (9), the provinces are divided into major grain-producing areas and non-major grain-producing areas according to regional attributes, and further examine the convergence of the high-quality agricultural development in each region, that is to investigate whether different regions will form different clubs in terms of high-quality agricultural development according to their differences in initial conditions, which will eventually lead to low level or high level of local convergence in the development of regions with similar internal conditions.

$$
\frac{1}{T} \ln \left(\frac{y_{i, t_{0}+\mathrm{T}}}{y_{i, t_{0}}}\right)=\rho W \frac{1}{T} \ln \left(\frac{y_{i, t_{0}+\mathrm{T}}}{y_{i, t_{0}}}\right)+B-\left(\frac{1-e^{-\beta T}}{T}\right) \ln \left(y_{i, t_{0}}\right)+\theta X_{i, t_{0}}+u_{i, t_{0+T}}
$$

\section{Results}

\subsection{Temporal-Spatial Evolution Characteristics}

Since the central Government put forward the idea of "subsidizing agriculture with industry" in 2003, the main characteristics of the spatial-temporal evolution of high-quality agricultural development in China are summarized as follows: first, in 2003, the high quality score of agriculture in the provincial region was generally low, but thanks to the advantages of green development and social coordination and sharing, the high quality development index score of agriculture in some western provinces was high. But the agricultural advantages of these provinces are gradually losing after 2007. Second, the provincial high-quality agricultural development index has increased from 2003 to 2017, but the fast-growing provinces are mainly in the eastern and central regions. Its highest score increased from 0.358 in 2003 to 0.496 in 2017 . Third, the provincial high-quality agricultural development index has obvious spatial differentiation characteristics, and the areas with slow development of high-quality agriculture mainly include western provinces such as Xinjiang, Gansu, Tibet and Yunnan. Fourth, its well-developed areas mainly include Beijing, Tianjin and Shanghai with relatively small agricultural population, Inner Mongolia and the three northeastern provinces with arable land endowment advantage, and Hunan, Hubei and Jiangxi in the Great Lakes region of the Yangtze River Basin and other provinces with water resources advantage. In general, after more than ten years of development, the advantages of the main grain producing areas have gradually emerged. Among the 13 main grain producing areas, 9 provinces rank high in agricultural high-quality development index, and spatially formed two advantageous zones for high-quality agricultural development in the Northeast Plain and the Yangtze River Basin.

\subsection{Provincial Differences and Changing Trend}

Table 2 reports the Theil index and its decomposition results for high-quality agricultural development. From 2003 to 2017, the Theil index showed a trend of declining volatility, and dropped from 0.412 in 2003 to 0.284 in 2017, which reflects that the difference in high-quality agricultural development in various regions is gradually shrinking. It is necessary to measure intra-regional and inter-regional differences and explore their share in overall differences, so as to promote the overall high-quality development of China's agriculture.

The province is divided into major grain-producing areas and non-major grain-producing areas, and further investigation of the overall difference decomposition results reflected by Theil index. Table 2 shows: (1) Provincial differences between the major areas and 
non-major areas also show a gradual decline. From 2003 to 2017, the difference between the provinces in the major areas dropped by about $34 \%$, and the difference between the provinces in the non-major areas dropped by about 25\%. (2) The difference of high-quality agricultural development in major areas is relatively small, while in non-major areas is large. From 2003 to

Table 2 The Theil index of provincial high-quality agricultural development and its contribution rate decomposition results
2017, the contribution of provincial differences in non-major areas to the overall difference remained at $58 \%$ to $64 \%$, which is maintained at $21-24 \%$ in major areas, and is maintained at $13 \%$ to $17 \%$ between the regions. It can be seen that the differences within the non-major producing areas are the main reason for the imbalance of agricultural development in China's provinces.

\begin{tabular}{|c|c|c|c|c|c|c|c|}
\hline \multirow[b]{2}{*}{ Year } & \multirow{2}{*}{$\begin{array}{l}\text { Total } \\
\text { Theil } \\
\text { index }\end{array}$} & \multicolumn{2}{|c|}{ Major areas } & \multicolumn{2}{|c|}{ Non-major areas } & \multirow{2}{*}{$\begin{array}{l}\text { Intra-regional } \\
\text { contribution }\end{array}$} & \multirow{2}{*}{$\begin{array}{l}\text { Inter-regional } \\
\text { contribution }\end{array}$} \\
\hline & & $\begin{array}{l}\text { Theil } \\
\text { index }\end{array}$ & contribution & $\begin{array}{l}\text { Theil } \\
\text { index }\end{array}$ & contribution & & \\
\hline 2003 & 0.412 & 0.212 & $24.2 \%$ & 0.455 & $58.5 \%$ & $82.7 \%$ & $17.3 \%$ \\
\hline 2007 & 0.340 & 0.163 & $22.1 \%$ & 0.394 & $62.4 \%$ & $84.5 \%$ & $15.5 \%$ \\
\hline 2008 & 0.337 & 0.158 & $21.7 \%$ & 0.399 & $63.6 \%$ & $85.3 \%$ & $14.7 \%$ \\
\hline 2009 & 0.336 & 0.154 & $21.1 \%$ & 0.400 & $64.2 \%$ & $85.3 \%$ & $14.7 \%$ \\
\hline 2010 & 0.323 & 0.152 & $21.7 \%$ & 0.374 & $62.3 \%$ & $84.0 \%$ & $16.0 \%$ \\
\hline 2011 & 0.320 & 0.152 & $22.0 \%$ & 0.372 & $62.5 \%$ & $84.6 \%$ & $15.4 \%$ \\
\hline 2012 & 0.322 & 0.158 & $22.7 \%$ & 0.372 & $62.0 \%$ & $84.7 \%$ & $15.3 \%$ \\
\hline 2013 & 0.308 & 0.148 & $22.5 \%$ & 0.363 & $62.8 \%$ & $85.3 \%$ & $14.7 \%$ \\
\hline 2014 & 0.312 & 0.151 & $22.5 \%$ & 0.364 & $62.4 \%$ & $85.0 \%$ & $15.0 \%$ \\
\hline 2015 & 0.296 & 0.152 & $24.0 \%$ & 0.341 & $61.3 \%$ & $85.3 \%$ & $14.7 \%$ \\
\hline 2016 & 0.290 & 0.144 & $23.1 \%$ & 0.335 & $61.8 \%$ & $84.9 \%$ & $15.1 \%$ \\
\hline 2017 & 0.284 & 0.140 & $23.2 \%$ & 0.342 & $64.0 \%$ & $87.2 \%$ & $12.8 \%$ \\
\hline
\end{tabular}

\subsection{Convergence of High-Quality Agricultural Development}

According to the analysis of Theil index, there exists a long-term problem of imbalanced regional agricultural development in China, but after more than ten years of development, this imbalance has appeared to be closed. It is helpful to put forward practical and effective policies, promote the coordinated development of regional agriculture, and enhance the high-quality development of agriculture in China by studying the provincial convergence characteristics of China's high-quality agricultural development. In Table 3, the absolute convergence equation 1 and the conditional convergence equation 1 report the estimation results of the uncontrolled individual difference and the year difference, while the absolute convergence equation 2 and the conditional convergence equation 2 report the estimation results of the controlling individual difference and the year difference. The absolute convergence rates of high-quality agricultural development are 0.064 and 0.049 , and the corresponding half-lives are about 11 and 15 years; the conditional convergence rates are 0.071 and 0.067, and the half-lives are 10 and 11 years, respectively.

Table 4 reports the test results of club convergence. Among them, the absolute and conditional convergence rates of high-quality agricultural development in major grain-producing areas are 0.060 and 0.095 , respectively, and the corresponding convergence half-lives are about 12 and 8 years; the absolute and relative convergence rates of high-quality agricultural development in non-major areas are 0.052 and 0.075 , respectively, and the corresponding convergence half-lives are about 14 years and 10 years. The convergence of the club for high-quality agricultural development is faster than the overall convergence, and the imbalance of agricultural development between the major grain-producing areas and non-major producing areas will become more and more obvious.

Table 3 Provincial convergence regression results of high-quality agricultural development

\begin{tabular}{|c|c|c|c|c|c|c|c|c|}
\hline & \multicolumn{2}{|c|}{$\begin{array}{l}\text { The absolute } \\
\text { convergence } \\
\text { equation } 1 \\
\end{array}$} & \multicolumn{2}{|c|}{$\begin{array}{c}\text { The conditional } \\
\text { convergence } \\
\text { equation } 1\end{array}$} & \multicolumn{2}{|c|}{$\begin{array}{l}\text { The absolute } \\
\text { convergence } \\
\text { equation } 2 \\
\end{array}$} & \multicolumn{2}{|c|}{$\begin{array}{c}\text { The conditional } \\
\text { convergence equation } \\
2 \\
\end{array}$} \\
\hline & $\begin{array}{c}\text { Coefficie } \\
\text { nt }\end{array}$ & t value & $\begin{array}{c}\text { Coefficie } \\
\text { nt }\end{array}$ & $\mathrm{t}$ value & $\begin{array}{c}\text { Coefficien } \\
\mathrm{t}\end{array}$ & $\mathrm{t}$ value & $\begin{array}{c}\text { Coefficien } \\
\mathrm{t}\end{array}$ & t value \\
\hline $\begin{array}{l}\text { Common } \\
\text { intercept }\end{array}$ & $-0.036^{* * *}$ & -9.033 & $-0.091^{* * *}$ & -2.700 & $-0.037^{* *}$ & -2.524 & $-0.072^{* * *}$ & -4.053 \\
\hline$L n y_{i, t 0}$ & $-0.062^{* * *}$ & -3.388 & $-0.069^{* * *}$ & -3.386 & $-0.048^{* * *}$ & -3.339 & $-0.065^{* * *}$ & -4.483 \\
\hline $\begin{array}{l}\text { The regional } \\
\text { output value } \\
\text { per capita }\end{array}$ & - & - & $0.013^{* * *}$ & 3.363 & - & $\longrightarrow$ & $0.011^{* * *}$ & 3.341 \\
\hline $\begin{array}{l}\text { Space lag } \\
\text { Control }\end{array}$ & $\begin{array}{c}0.446^{* * *} \\
\text { no }\end{array}$ & 6.465 & $\begin{array}{c}0.409^{* * *} \\
\text { no }\end{array}$ & 6.360 & $\begin{array}{c}0.479^{* * *} \\
\text { yes }\end{array}$ & 7.220 & $\begin{array}{c}0.477^{* * *} \\
\text { yes }\end{array}$ & 7.220 \\
\hline
\end{tabular}


individual

difference

Control year

difference

no

\begin{tabular}{ccc} 
no & yes & yes \\
310 & 310 & 310 \\
\hline 0.248 & 0.291 & 0.315 \\
0.071 & 0.049 & 0.067 \\
9.695 & 14.091 & 10.313 \\
\hline
\end{tabular}

\begin{tabular}{ccccc} 
Observations & 310 & 310 & 310 & 310 \\
\hline Adj-R & 0.221 & 0.248 & 0.291 & 0.315 \\
Convergence & 0.064 & 0.071 & 0.049 & 0.067 \\
Half-lives & 10.830 & 9.695 & 14.091 & 10.313
\end{tabular}

Note: ${ }^{*} 10 \%$ level, $* * 5 \%$ level, ${ }^{* * *} 1 \%$ level, and the regional output value per capita takes the logarithm

Table 4 Convergence regression results of provincial clubs for high-quality agricultural development

\begin{tabular}{|c|c|c|c|c|c|c|c|c|}
\hline & \multicolumn{2}{|c|}{$\begin{array}{c}\text { Absolute } \\
\text { convergence of } \\
\text { major areas }\end{array}$} & \multicolumn{2}{|c|}{$\begin{array}{c}\text { Conditional } \\
\text { convergence of } \\
\text { major areas } \\
\end{array}$} & \multicolumn{2}{|c|}{$\begin{array}{c}\text { Absolute } \\
\text { convergence of } \\
\text { non-major areas }\end{array}$} & \multicolumn{2}{|c|}{$\begin{array}{c}\text { Conditional } \\
\text { convergence of } \\
\text { non-major areas }\end{array}$} \\
\hline & $\begin{array}{c}\text { Coefficie } \\
\text { nt }\end{array}$ & $\mathrm{t}$ value & $\begin{array}{c}\text { Coefficie } \\
n t\end{array}$ & t value & $\begin{array}{c}\text { Coefficien } \\
\mathrm{t}\end{array}$ & t value & Coefficient & t value \\
\hline $\begin{array}{l}\text { Common } \\
\text { intercept }\end{array}$ & $-0.048^{* *}$ & -2.337 & $-0.093^{* * *}$ & -2.619 & -0.037 & -1.523 & $-0.081^{* * *}$ & -3.478 \\
\hline$L n y_{i, t 0}$ & $-0.058^{* * *}$ & -2.982 & $-0.091^{* * *}$ & -3.094 & $-0.051^{* *}$ & -2.212 & $-0.072^{* * *}$ & -3.827 \\
\hline $\begin{array}{l}\text { The regional } \\
\text { output value } \\
\text { per capita }\end{array}$ & 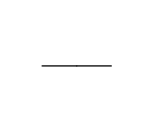 & $\longrightarrow$ & $0.016^{* *}$ & 2.118 & - & $\longrightarrow$ & $0.011^{* * *}$ & 2.798 \\
\hline $\begin{array}{l}\text { Space lag } \\
\text { Control }\end{array}$ & $0.410^{* * *}$ & 4.730 & $0.307^{* * *}$ & 2.792 & $0.311^{* * *}$ & 2.844 & $0.382^{* * *}$ & 4.310 \\
\hline $\begin{array}{l}\text { individual } \\
\text { difference }\end{array}$ & yes & & yes & & yes & & Yes & \\
\hline $\begin{array}{l}\text { Control year } \\
\text { difference }\end{array}$ & yes & & yes & & yes & & Yes & \\
\hline Observations & 130 & & 130 & & 180 & & 180 & \\
\hline $\operatorname{Adj}-R^{2}$ & 0.133 & & 0.162 & & 0.195 & & 0.229 & \\
\hline Convergence & 0.060 & & 0.095 & & 0.052 & & 0.075 & \\
\hline Half-lives & 11.601 & & 7.265 & & 13.242 & & 9.276 & \\
\hline
\end{tabular}

Note: * $10 \%$ level, ** 5\% level, *** $1 \%$ level, and the regional output value per capita takes the logarithm

\section{Conclusions and discussion}

First, from 2003 to 2017 , the quality of China's agricultural development has steadily improved, reflected in the fact that main grain production areas are higher than that in non-main production areas, the Northeast Plain and the Yangtze River Basin are higher than other regions, and regions rich in cultivated land and water resources have gradually turned their comparative advantages into development advantages. Second, it shares the characteristics of conditional convergence in China, while the main grain-producing areas and non-main-producing areas also have the characteristics of club convergence, the conditional convergence rates of them were 0.095 and 0.075 , respectively, and the convergence half-lives were approximately 8 years and 10 years, respectively. Economic growth can promote the high-quality development of agriculture and is the guarantee condition for the convergence. Considering the future slowdown in economic growth, the convergence half-life may take longer. Third, the problems in some eastern provinces are mainly manifested in the uneven urban-rural distribution of public services such as education, health care, and social security, and agricultural output relies on high inputs of chemical fertilizers, pesticides, and petrochemical energy. The improvement of agricultural efficiency in the western region has been slow, and the income gap between urban and rural areas is higher than that in the central and eastern regions. The backward economic development is unable to realize the "subsidization of agriculture by industry", resulting in the lack of material guarantee for high-quality agricultural development.

Based on the above conclusions, the corresponding policy recommendations are put forward, including contents as follows: (1) developing modern agriculture and improving the industrial system, (2) promoting technological innovation and transforming business model, (3) Attaching importance to the protection of agricultural ecology and environment, (4) implementing the concept of sharing and bringing benefits to rural areas.

\section{Acknowledgments}

This work was supported by the Humanities and Social Sciences Project of Jiangxi province (GL20138).

\section{References}

1. Zhang Junkuo, Hou Yongzhi, et al. The Golds and Strategy Path of High-quality Development[J]. Management World, 2019(7):1-7. 
2. Jin Bei. Study on the "High-Quality Development" Economics $[\mathrm{J}]$. China Industrial Economics, 2018(4):5-18.

3. He Lifeng. Implementing the New Concept of Development to Lead China's Economy to High-quality Development[J]. Macroeconomic Management, 2018(04):4-5+14.

4. Shao S, Luan R, Yang Z, et al. Does Directed Technological Change Get Greener: Empirical Evidence From Shanghai's Industrial Green Development Transformation[J]. Ecological indicators, 2016(69): 758-770.

5. Han Changfu. Vigorously Promote Quality and Green Agriculture, and Accelerate the Realization of High-Quality Agricultural Development[N]. Gansu Agriculture,2018-02-27.

6. Barro R J, Sala-I-Martin X . Convergence[J]. Journal of Political Economy, 1992, 100:223-251.

7. Young A T, Higgins M J, Levy D. Sigma Convergence versus Beta Convergence: Evidence from U.S. County-Level Data[J]. Journal of Money, Credit and Banking, 2008, 40(5):1083-1093

8. XU Hong, ZHAO Yu. Research on Economic Growth Convergence of Yangtze River Economic Belt Based on Spatial Model [J]. Soft Science, 2015, 29(08):77-81. 